\title{
KEPEMANDUAN DAN PENINGKATAN KEMAMPUAN BAHASA INGGRIS PENGELOLA KAWASAN EKOWISATA GUNUNG API PURBA NGLANGGERAN
}

\author{
Sucipto \\ Fakultas Ekonomi Program Studi Manajemen Pariwisata Universitas Terbuka \\ Email: suciptosucipto@ecampus.ut.ac.id
}

\begin{abstract}
Abstrak
Sejak ditetapkannya Gunung Api Purba Nglanggeran sebagai bagian dari geopark gunung sewu otomati masuk dalam geopark network di level internasional. Untuk itu, pelatihan bahasa inggris perlu dilakukan untuk menyiapkan SDM yang berkualitas dan meningkatkan keterampilan komunikasi serta meningkatkan standar pelayanan terhadap wisatawan mancanegara. Melihat kualitas SDM yang bervariasi maka metode yang dipilih dalam pelatihan yaitu, reading, vocabulary, diskusi, role play dan native speaker. Dampak dari pelatihan yang dilaksanakan dua bulan, pengelola sudah memiliki keberanian memandu wisatawan mancanegara, mampu menjelaskan secara sederhana mengenai objek wisata yang ada. Selalin itu, sudah memiliki kemampuan dalam membaca teks serta memilik hafalan kosa kota yang memadai sesuai dengan objek dan daya tarik wisata di Kawasan Ekowisata Gunung Api Purba Nglanggeran. Pengelola perlu memperkaya kosa kata, membiasakan komunikasi dalam Bahasa Inggris. Kemampuan Bahasa Inggris dapat meningkatkan pelayanan pengelola terhadap para wisatawan mancanegara, dan pengelola mampu menyampaikan informasi dengan baik. Pelatihan ini diakhiri dengan menjaring pendapat dari peserta dan pengeloa yang terlibat, hal tersebut sebagai bahan evaluasi. Hasil evaluasi menunjukan $99 \%$ bahwa materi yang disampaikan sangat aplikatif dan mudah dipahami. Dari 20 orang yang peningkatannya siginifikan yaitu 16 peserta, sedangkan yang 4 orang perlu belajar lebih giat lagi.
\end{abstract}

Kata Kunci: Ekowisata, Gunung Api Purba Nglanggeran, Kepemanduan

\begin{abstract}
Since the enactment of the Nglanggeran Ancient Volcano as part of the sewu automatic geopark enter the geopark network at the international level. For this reason, English language training needs to be done to prepare quality human resources and improve communication skills and improve service standards for foreign tourists. Seeing the varied quality of human resources, the methods chosen in the training are reading, vocabulary, discussion, role play and native speaker. The impact of the training which was held in two months, the manager already has the courage to guide foreign tourists, able to explain simply about existing tourist attractions. In addition, it already has the ability to read texts and have adequate vocabulary in accordance with the objects and tourist attractions in the Nglanggeran Ancient Volcano Ecotourism Region. Managers need to enrich vocabulary, familiarize communication in English. English language skills can improve management services for foreign tourists, and managers are able to convey information well. The training ended with soliciting the opinions of the participants and pengeloa involved, as an evaluation material. Evaluation results show $99 \%$ that the material presented is very applicable and easy to understand. Of the 20 people with a significant increase of 16 participants, while 4 people need to study harder.
\end{abstract}

Keywords: Ecotoursim, Nglanggeran Ancient Volcano, Guiding 


\section{PENDAHULUAN}

Gunung Api Purba Nglanggeran yang terdapat di Kabupaten Gunungkidul Yogyakarta sejak akhir 2010 diusulkan untuk menjadi geopark pertama di Indonesia. Sejumlah geolog dan perwakilan Perserikatan Bangsa-Bangsa untuk pendidikan dan ilmu pengetahuan (United Nations Educational, Scientific and Cultural Organization) UNESCO memberikan penilaian bahwa kawasan ini pantas menjadi geopark (Baiquni, 2015).k. Pada akhir tahun 2015 secara resmi ditetapkan menjadi Geopark (Profil Desa Wisata Gunung Api Purba Nglanggeran, 2015).

Sejak ditetapkannya Gunung Api Purba sebagai bagian dari Geopark Gunungsewu secara otomatis masuk kedalam jaringan geopark dunia dan sudah beberapa tahun masuk dalam jaringan ekowisata dunia. Hal tersebut menjadi tantangan bagi pengelola untuk melakukan improvisasi dan pengembangan untuk meningkatkan daya saing dan persaingan dunia.

Salah satu kendala dalam proses pengelolaan dan pengembangan geopark gunung sewu yaitu sumber daya manusia yang mampu mengelola keseluruhan, dan memberikan pelayanan prima kepada wisatawan yang datang (Antaranews.com, 2016, TribunJogja.com 2016, dan Bernas.id, 2016). Widodo (2016) penguasaan bahasa Inggris menjadi salah satu kelemahan SDM pariwisata Indonesia. Hal tersebut menjadi masalah utama dan daya saing Indonesia rendah di tingkat ASEAN. Pelatihan kepemanduan dan Bahasa Inggris dilaksanakan untuk meningkatkan kemampuan pengelola dan pemandu lokal Kawasan Ekowisata Gunung Api Purba Nglanggeran.

Oleh karena itu, peningkatan kualitas SDM (bidang kemampuan bahasa inggris) menjadi salah satu kunci untuk memenangkan persaingan global yang semakin kompetitif. Prasyarat untuk itu adalah sistem pendidikan dan pelatihan (Kusworo dan Damanik, 2002).
Gunung Api Purba yang sudah masuk dalam jaringan internasional baik dari sisi geopark dan ekowisata membutuhakn pelatihan dalam memberikan pelayanan secara professional dengan menggunakan bahasa inggris dalam berkomunikasi. Pelatihan bahasa inggris menjadi penting dalam meningkatkan kapasitas pengelola dalam menjalin komunikasi dengan wisatawan asing.

Selain itu pelatihan bahasa inggris merupakan salah satu upaya peningkatkan kualitas SDM dalam pembangunan geopark gunungsewu Kabupaten Gunungkidul dan meningkatkan kemampuan masyarakat lokal dalam berbahasa inggris. Hal tersebut akan menjadi modal dalam merespon pasar persaingan di kanca internasional (Sucipto, 2016).

\section{METODE PELAKSANAAN}

Kegiatan pelatihan bahasa Inggris dimulai dengan sosialisasi kegiatan kepada pengelola dengan tujuan untuk mendapatkan gambar dan memetakan kemampuan penggunaan bahasa inggris.

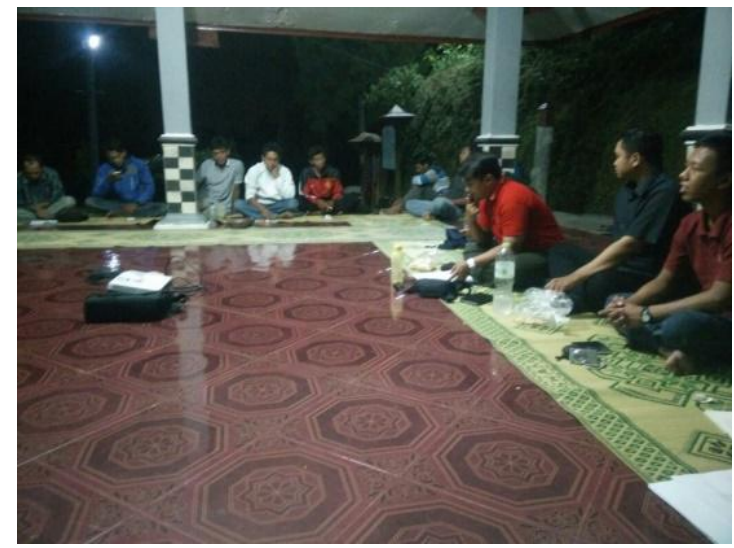

Gambar 1. Sosialisasi Pelaksanaan Pelatihan

Peserta yang mengikuti pelatihan bahasa berjumlah 20 orang yang berasal dari pengelola (semua berasal dari masyarakat sekitar Kawasan Ekowisata Gunung Api Purba Nglanggeran). 


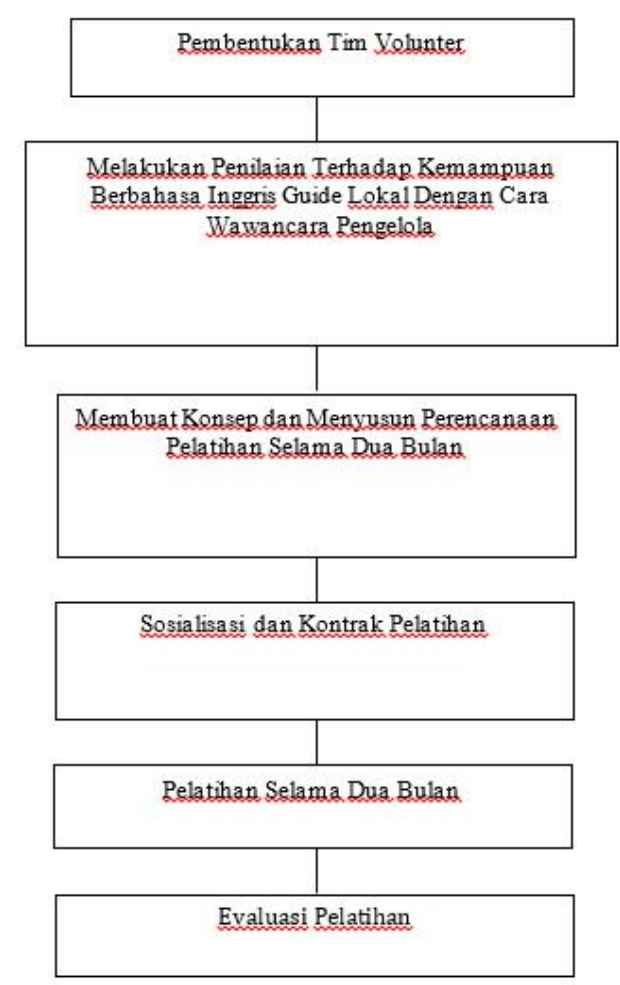

Bagan 1. Alur Pelatihan

Secara praktis pelatihan dilaksanakan dengan beberapa metode yaitu, pertama, reading para instruktur membacakan teks hasil translate dari deskripsi objek-objek di sekitar kawasan dan para peserta mengikuti. Dan setiap peserta disuruh membaca ulang untuk mengetahui cara membacanya sudah bener atau belum. Kedua, vocabulary, instruktur menulis setiap kata yang tidak dimengerti oleh peserta dan kemudian dihafalkan.

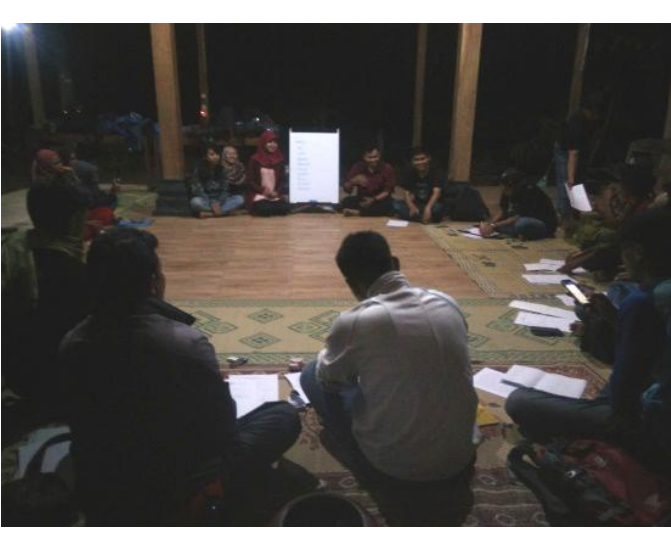

Gambar 2. Penggunaan metode vocabulary

Ketiga, role play setiap sesi dalam pertemua peserta diajak untuk bermain peran yaitu ada yang menjadi pemandu lokal dan wisatawan.

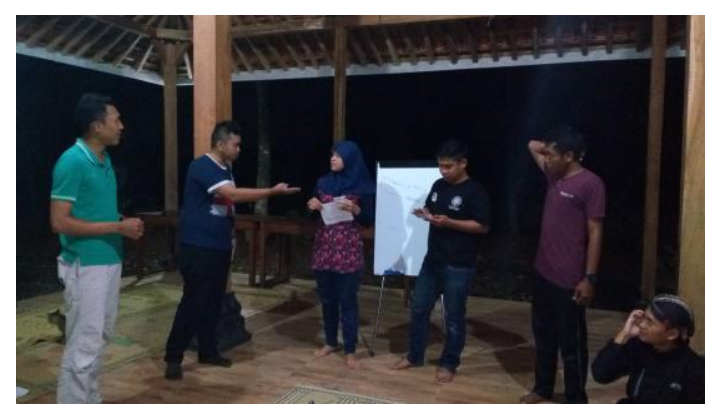

Gambar 3. Perapan Metode Role Play

Keempat, native speaker mendatangkan bule/tourist dari Thailand dan Mesir. Setiap peserta menjawab pertanyaan yang disampaikan.

\section{HASIL DAN PEMBAHASAN}

Hasil pelaksanaan kegiatan pelatihan sebagai berikut:

a. Pembentukam Tim

Pembentukan tim dilakukan dengan ketentua, memiliki kemampuan Bahasa Inggris Aktif, memeliki pengetahuan tentang pariwisata, memiliki kemauan untuk melakukan community development. Hal ini dilakukan agar semua tim memiliki pemahaman dan persepsi yang sama terutama ketika pelatihan berjalan.

b. Assesment Pemandu Lokal dan Pengelola 
Untuk mengetahui sejau mana kemampuan Bahasa Inggris pemadu lokal dengan cara melakukan wawancara pengelola dan sekaligus pemandunya. Selain itu juga, menanyakan berapa orang yang pernah mengikut les, dan yang belum sama sekali. Sehingga bisa dipetakan kemampuan Bahasa Ingrisnya.

c. Konsep Pelatihan

Pelatihan dilaksanakan sesuai dengan kebutuhan pemandu lokal dan pengelola. Dan pelatihan ini fokus kepada pengenalan kota kata yang akan digunakan untuk menerangkan seputar Gunung Api Purba dan lingkungan sekitar sehingga pemandu/masyarakat bisa dengan mudah mempratikan dalam Bahasa Inggris tersebut.

d. Sosialisasi dan Kontrak Pelatihan

Agar pengelola dan calon peserta mengetahui tujuan dan maksud serta arah pelatihan maka dilakukan sosialisasi terlebih dahulu. Dalam sosialisasi ini juga disampaikan mengenai aturanaturan selama pelatihan agar setiap peserta bisa mengikuti dengan baik. Peserta dibatasi jumlah maksimal 20 orang, dan setiap peserta harus memiliki komitmen yang tinggi untuk meningkatkan kemampuan Bahasa Inggrisnya.

e. Pelatihan

Pelatihan bahasa Inggris di Kawasan Ekowisata Gunung Api Purba Nglanggeran dilaksanakan selama 2 bulan. Selama pelatihan berlangsung mendapatkan dukungan penuh dan antusias peserta sangat tinggi.

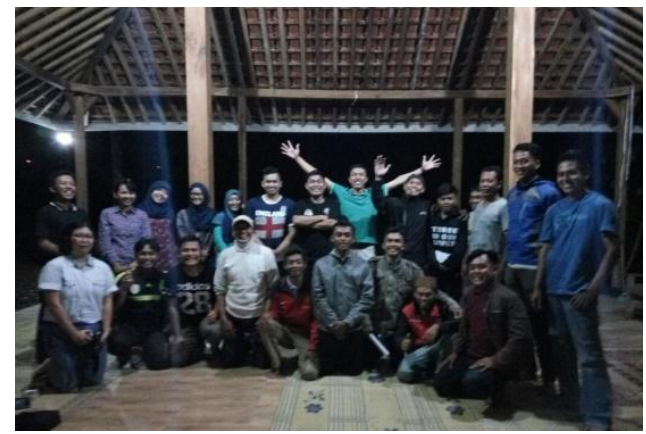

Gambar 4. Peserta Pelatihan Bahasa Inggris
Dalam waktu yang sangat singkat peningkatan kemampuan komunikasi bahasa inggris sangat signifikan bahkan bisa dibilang sangat "luar biasa". Para peserta memiliki kepercayaan dan keberanian untuk memandu wisatawan asing, misalnya sudah bisa menunjukan jalan misalnya, "turn left, turn light, tjunction, intersection, crossroad, junctions".

1. Go straight, go on, go ahead

2. Turn left, turn light

3. Behind, beside, in front of, next to

4. T-junction, intersection, crossroad, junctions

5. On the left side, on the right side

6. Above, under

7. Towards

8. A climb, a slope

9. Dead end

10. Close to, near by, far from

11. About, around, approximately

12. First, second, third

13. After that

14. You will find

15. When you reach

16. Mosque, hall, bridge, parking area

17. This way, that way, over there

18. Follow me

Gambar 5. Salah Satu Materi Dalam Metode Vocabulary

Pasca pelatihan kepemanduan dan bahasa, pengelola merasa tenang ketika ada wisatawan asing/mancanegara yang datang karena sudah mampu menjelaskan secara sederhana mengenai objek-objek yang ada di sekitar dan mampu menjelaskan kondisi sosial, budaya masyarakat dan spot-spot dari objek wisata yang ada di Kawasan Ekowisata Gunung Api Purba Nglanggeran.. Misalnya, pengelola sudah bisa menjelaskan mengenai daya tarik wisata berupa matahari terbit di puncak Gunung Api Purba Nglanggeran.

Untuk menunjang komunikasi bahasa Inggris maka perlu terus ditambah mengenai vocabulary, karena semakin banyak yang dihafal maka akan semakin 
lancar untuk komunikasi. Selian itu terus dibiasakan untuk senantiasa komunikasi dengan menggunakan bahasa inggris. Karena masih ada sebagian pengelola yang merasa malu untuk menggunakannya. Sehingga itu bisa menjadi salah faktor penghambat untuk membiasakan dan meningkatkan kemampuan bahasa inggrisnya.

Secara umum pelatihan yang dilakukan lebih menekankan kepada praktik dan penghafalan vocabulary. Selain itu juga, harus memiliki keberanian untuk selalu mencoba dan memperaktikan sampai akhirnya terbiasa dengan bahasa Inggris.

f. Evaluasi

Pada akhir pelatihan dilakukan evaluasi bersama perserta dan pengelola serta tim pelatihan. Menanyakan langsung kepada peserta dan pengelola mengenai keseuaian materi yang disampaikan, metode yang digunakan serta kemampuan para tim dalam menyampaikan materi. Selain itu juga menanyakan peningkatan kemampuan bahasanya Inggrisnya.

Peserta dan pengelola memberikan penilaian bahwa 99\% materi yang disampiakan sangat sesuai dan sangat aplikatif karena dapat digunakan langsung untuk memberikan informasi kepada wisatawan. Dari 20 orang yang peningkatannya siginifikan yaitu 16 peserta, sedangkan yang 5 orang perlu belajar lebih giat lagi.

\section{KESIMPULAN}

Hasil pelatihan bisa dirasakan langsung oleh para peserta. Dari 20 orang yang mengikuti pelatihan sudah bisa menggunakan bahasa inggris 16 orang sedangkan yang 4 orang masih belum maksimal karena tidak begitu semangat dalam mengikuti pelatihan dan tidak setiap saat datang pelatihan sesaui dengan jadwal yang disepakati. Hasil Namun, masih perlu dilakukan pelatihan lanjutan agar kemampuannya semakin meningkat dan bisa sangat mahir dalam memandu.

\section{UCAPAN TERIMAKASIH}

Acara kepemanduan dan peningkatan kemampuan bahasa inggris pengelola Kawasan Ekowisata Gunung Api Purba Nglanggeran berlangsung sesuai dengan rencana berkat kerjasama beberapa pihak. Terimakasih kepada seluruh tim dari STORM yang sudah merancang pelatihan ini dengan simpel namun materinya sangat aplikatif. Selain itu instruknya sangat kompeten dalam kepemanduan dan bahasa inggris.

Terimakasih yang tak terhingga disampaikan kepada seluruh pengelola Kawasan Ekowisata Gunung Api Purba Nglanggeran beserta masyarakat atas partisipasinya dan fasilitas berupa penginapan (homestay) dan akses ke seluruh kawasan.

\section{REFERENSI}

Antaranews.com. 2016. Pengelolaan Geopark Gunung Sewu Terkendala SDM Pengelola Geosite. https://jogja.antaranews.com/berita/3397 70/pengelolaan-geopark-gunungsewuterkendala-sdm-pengelola-geosite. Diakses pada tanggal 11 Juni 2020.

Baiquni, M. 2015. Model The STARS (Sustainable Tourism Action Research School) Indikator Pembangunan Pariwisata Berbasis Masyarakat di Kawasan Gunung Api Purba Nglanggeran, Kawasan Geopark Nasional Gunung Kidul. Laporan Penelitian Hibah Dosen Sekolah Pascasarjana Universitas Gadjah Mada. Program Studi Kajian Pariwisata.

Bernas.id. 2016. SDM Menjadi Kendala Pengelolaan Geopark Gunung Sewu Gunungkidul.

https://www.bernas.id/15755-sdmmenjadi-kendala-pengelolaan-geoparkgunungsewu-gunungkidul-.html. Diakses pada tanggal 11 Juni 2020.

Kusworo, H A dan Damanik, J. 2002. Pengembangan SDM Pariwisata Daerah: Agendan Kebijakan untuk Pembuat Kebijakan. Jurnal Ilmu Sosial dan Ilmu Politik. Volume 6, No. 1. Hal. 105-120. 
Profil Desa Wisata Gunung Api Purba Nglanggeran, 2015

Sucipto. 2016. Pemahaman Pemangku Kepentingan Dalam Pengelolaan Kawasan Ekowisata Gunung Api Purba Nglanggeran. Tesis. Sekolah Pascasarjana Universitas Gadjah Mada.

TribunJogja.com 2016. Pengelolaan Geopark Gunung Sewu Terkendala Ketersediaan Sarpras dan Kualitas SDM. https://jogja.tribunnews.com/2016/05/24 /pengelolaan-geopark-gunungsewuterkendala-ketersediaan-sarpras-dankualitas-sdm?page $=2$. Diakses pada tanggal 5 April 2020.

Widodo, Wahyu Setyo. 2016. Tiga Masalah SDM Pariwisata Indonesia Bersaing di Tingkat Global. Travel.detik.com. Diakses pada tanggal 5 April 2020. 